\title{
LONG-TIME INVESTIGATION OF CEMENT COMPOSITE MATERIAL WITH MICRONIZED WASTE MARBLE POWDER: DYNAMIC MODULES
}

\author{
ZDENĚK PROŠEK ${ }^{a, b, *}$, JAROSLAV TOPIČ ${ }^{a}$ \\ ${ }^{a}$ Czech Technical University in Prague, Faculty of Civil Engineering, Thákurova 7, 166 29 Prague 6, Czech \\ Republic \\ ${ }^{b}$ University Centre for Energy Efficient Buildings, Czech Technical University in Prague, Třinecká 1024, \\ 27343 Buštěhrad, Czech Republic \\ * corresponding author: zdenek.prosek@fsv.cvut.cz
}

\begin{abstract}
This article focus on "blended cement". The blended cement was created by using waste marble powder (WMP) as a partial replacement for cement. We investigated the influence of WMP on the developing of the dynamic modulus of elasticity and the dynamic shear modulus in time. Four different cement composites with WMP as a partial replacement for cement were studied (5, 10, 15 and 50 wt. \%) together with reference samples. Dynamic modulus of elasticity was monitored during the first 377 days since manufacture by use of non-destructive testing (resonance method). The results showed that WMP in a small amount had a no effect on the dynamic modulus of elasticity and the dynamic shear modulus.
\end{abstract}

KEYworDs: Micronized marble powder, cement composites, mechanical properties, long-time investigation.

\section{INTRODUCTION}

The recycled materials are usually used as an option to non-renewable resources. The problem is mainly variability of these materials, for this cause, is mainly applied to transport infrastructure [1. Examples of the use of waste or recycled materials were spelled out in the study, e.g. [2] another primarily utilizing waste from marble industry, directly waste marble sludge. The waste marble sludge generated during the cutting block, or during the finishing process making an environmental problem. The generation of waste is making environmental problems as the valuable national wealth is getting wasted mainly due to lack of management and lack of technology, air contamination, water contamination and loss of vegetation and fauna [5].

The amount of this waste was calculated for the section of The Shaq El Thoaban, Egypt to one million tons per year 6] and for the section of Estremoz Anticline, Alentejo, Portugal to 600 thousand tons per year [7]. Both areas have approximately the same production of marble stone, but the technical, operational and management practices in the industry are less developed in area Shaq El Thoaban and they have contributed significantly to greater waste generation. From all the waste produced from marble enterprise, only 10 to $20 \%$ is used in construction. The remainder is refused and accumulated in mounds marble waste close to the extraction quarries [8, 9]. There are some articles that deal with utilized the marble sludge as the replacement for cement in producing the blended cement. The first study found that the addition of the marble sludge to the cement composite is changed crystals portlandite [10. The second study showed the morphology of the internal structures of cement pastes with and without marble sludge is identical 11. In all case, marble sludge in a small amount had a good influence on mechanical properties [12, 13]. Grains of marble sludge clump together into lumps and thus grains of marble sludge are not homogeneously distributed in the mixture. New option to reduce or restrict this effect is the use of high-speed milling from Lavaris Ltd. The resulting output is waste marble powder (WMP) and it has better mechanical properties than marble sludge [14]. High-speed milling method separates all the grains of marble sludge. The high-speed milling method was successfully applied for micronized of recycled concrete [15.

\section{MATERIALS AND SAMPLES}

The cement used was a commercial CEM I 42.5R (Radotín, Czech Republic) ordinary Portland cement. The WMP used was obtained from the processing of limestone marble in the Czech Republic as unsorted waste (Beroun, Jež Ltd.), which was micronized using a high-speed mill from Lavaris Ltd. (Libčice, Czech Republic). The micronized marble powder with fraction $0-40 \mathrm{~mm}$ had an average grain and mean grain size of 9.74 and 4.59 microns, respectively.

The testing mixtures were designed to keep the identical workability as the fresh reference mixture. The consistency of the mixtures was determined by workability slump test $20(\mathrm{~d} 20)$, (Table 1 ). The water ratio is determined as water to cement and marble pow- 


\begin{tabular}{ccccccc}
\hline Set/ Material & $\begin{array}{c}\text { CEM I } \\
\text { [wt. \%] }\end{array}$ & $\begin{array}{c}\text { WMP } \\
\text { [wt. \%] }\end{array}$ & $\begin{array}{c}\text { Water } \\
\text { ratio [-] }\end{array}$ & $\begin{array}{c}\text { Flow expansion } \\
\text { test d20 [mm] }\end{array}$ & $\begin{array}{c}\text { Bulk density } \\
{\left[\mathbf{k g}^{-3} \text {.m }\right.}\end{array}$ & $\begin{array}{c}\text { Shrinkage } \\
{[\%]}\end{array}$ \\
\hline ref. WMP_0 & 100 & 0 & 0.35 & 190 & $1919 \pm 5$ & $0.19 \pm 0.06$ \\
WMP_5 & 95 & 5 & 0.32 & 190 & $1915 \pm 6$ & $0.27 \pm 0.11$ \\
WMP_10 & 90 & 10 & 0.315 & 190 & $1920 \pm 3$ & $0.14 \pm 0.05$ \\
WMP_15 & 85 & 15 & 0.31 & 190 & $1879 \pm 6$ & $0.21 \pm 0.07$ \\
WMP_50 & 50 & 50 & 0.305 & 190 & $1760 \pm 8$ & $0.45 \pm 0.16$ \\
\hline
\end{tabular}

TABLE 1. Composition of the individual set/mixtures.

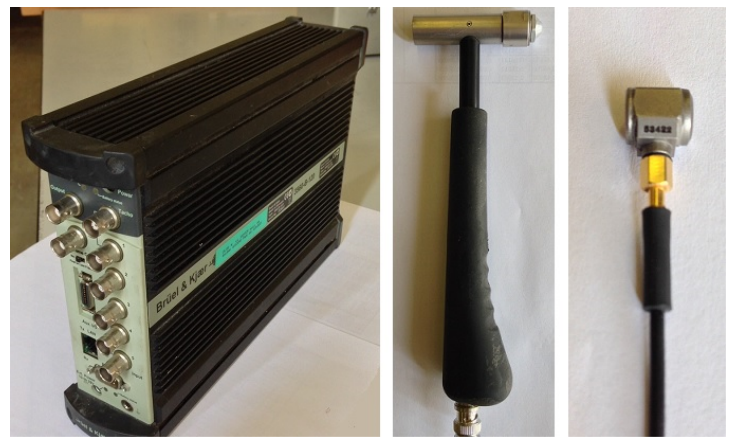

FiguRE 1. Experimental set-up for the Resonance method.

der weight ratio. Cement was replaced by the waste micronized marble powder by the amount of 5,10 , 15 and 50 wt. percent (Table 1). Mixtures made according to Table 1 were cast to the rectangular molds with dimensions $40 \times 40 \times 160 \mathrm{~mm}$. All the rectangular molds were measured their dimensions before the mixture was implemented to the mold. These values were applied for determine shrinkage. After casting, these specimens were kept in the molds for $24 \mathrm{~h}$ at the laboratory with the temperature $22{ }^{\circ} \mathrm{C}$. Each set consisted of 6 specimens. After demolding, these specimens were deposited in a laboratory environment at $22 \pm 1{ }^{\circ} \mathrm{C}$ and relative humidity $50 \pm 2 \%$.

\section{EXPERIMENTAL METHODS}

The dynamic modulus of elasticity and the dynamic shear modulus were observed using the resonance method, based on determinations of the natural frequency measured on specimens. Resonance method is a non-destructive test. The last measurement was made after 377 days.

The resonance method was carried out using the measurement line from Brüel \& Kjær, consisting of a measurement station type 3560-B-120, type 4519003 acceleration transducers, an 8206 impact hammer type and a control computer with software PULSE LabShop (Figure 1). The resonance method requires information about the dimensions and the weight of each sample earlier than testing was applied. The response signals were transformed from the time to the frequency using the Fast Fourier Transform. The Frequency Response Function (FRF) was determined as the ratio of the response and the excitation force in the frequency. The proper basic natural frequencies were evaluated from the FRFs. Then the dynamic modulus of elasticity and the dynamic shear modulus were evaluated based on the basic longitudinal natural frequency of the samples and the basic torsional natural frequency of the sample, respectively [16, 17].

\section{Result And Discussion}

Figure 2 shows the evolution of the bulk density, where the free water evaporates over time, thereby changing the bulk density of the samples. Figure 3 and 4 shows the evolution of the dynamic shear modulus and the dynamic modulus of elasticity, respectively over time. All of the samples exhibit the steepest increase of the modulus of elasticity in the first day. After the first day, the cement composite rapidly lost the value of dynamic modulus of elasticity. This was due to loss of weight of the sample by natural drying.This phenomenon can be explained by gauging water evaporates from the sample and changes the inner environment in which the wave from the pulse method spreads. The values were stabilized between 7 and 377 days. The curves got smaller decline modulus between 7 and 377 days.

There is a noticeable relation between the value of modulus of elasticity and the amount of WMP used in the mixture. The highest modulus had the reference mixture WMP_0 , namely $16.8 \mathrm{GPa}$ for 28 days old samples and 16.0 GPa fot 377 days old samples in the case of the dynamic modulus of elasticity and the dynamic shear modulus was $7.3 \mathrm{GPa}$ for 28 days old samples and 7.1 for 377 days old samples. The lowest value of modulus had the mixture with $50 \mathrm{wt}$. \% of WMP, namely 14.6 GPa for 28 days old samples and 13.9 GPa for 377 days old samples in the case of the dynamic modulus of elasticity and the dynamic shear modulus was $5.9 \mathrm{GPa}$ for 28 and 377 days old samples.

\section{Conclusions}

This work is focused on the mechanical properties of the cement composites composed of Portland cement and different amounts of waste marble powder. Based on the results it can be concluded that:

- All of the samples exhibit the steepest increase of the modulus in the first day. 


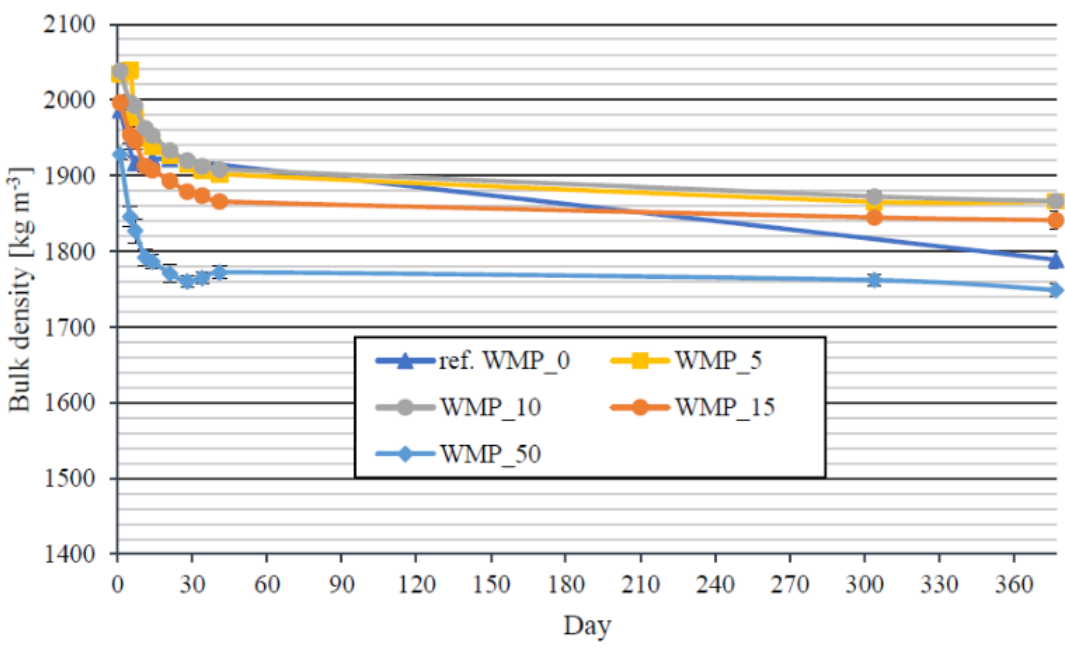

Figure 2. Time dependence of Bulk density (with standard deviation).

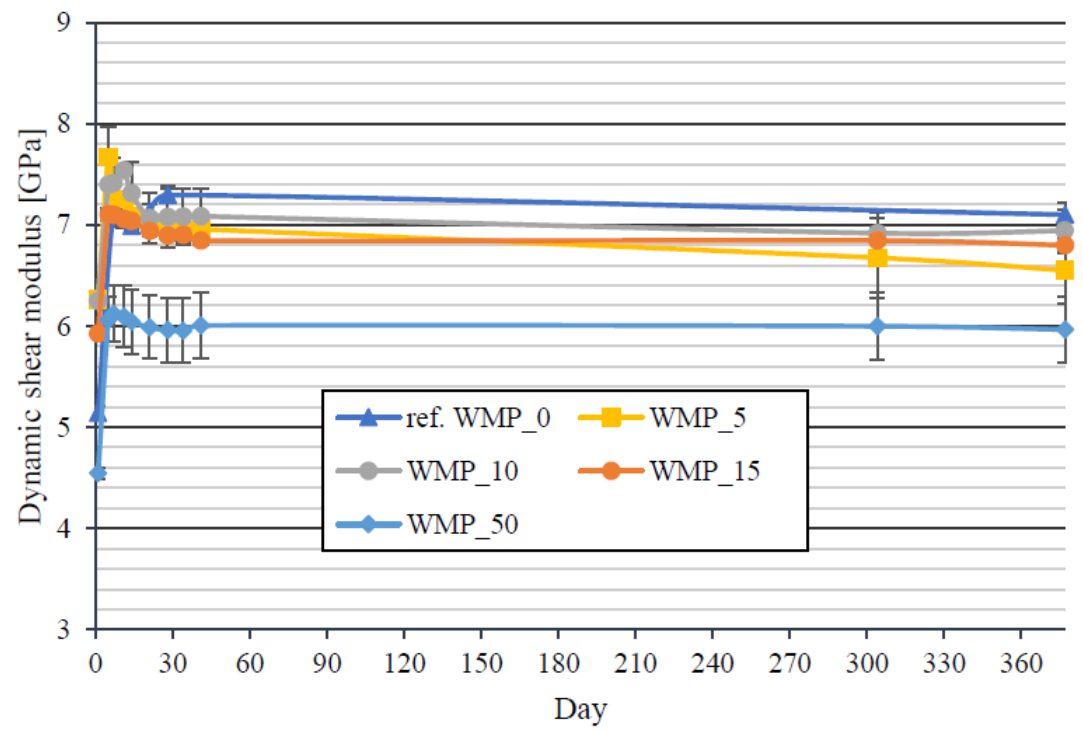

Figure 3. Time dependence of dynamic shear modulus (with standard deviation).

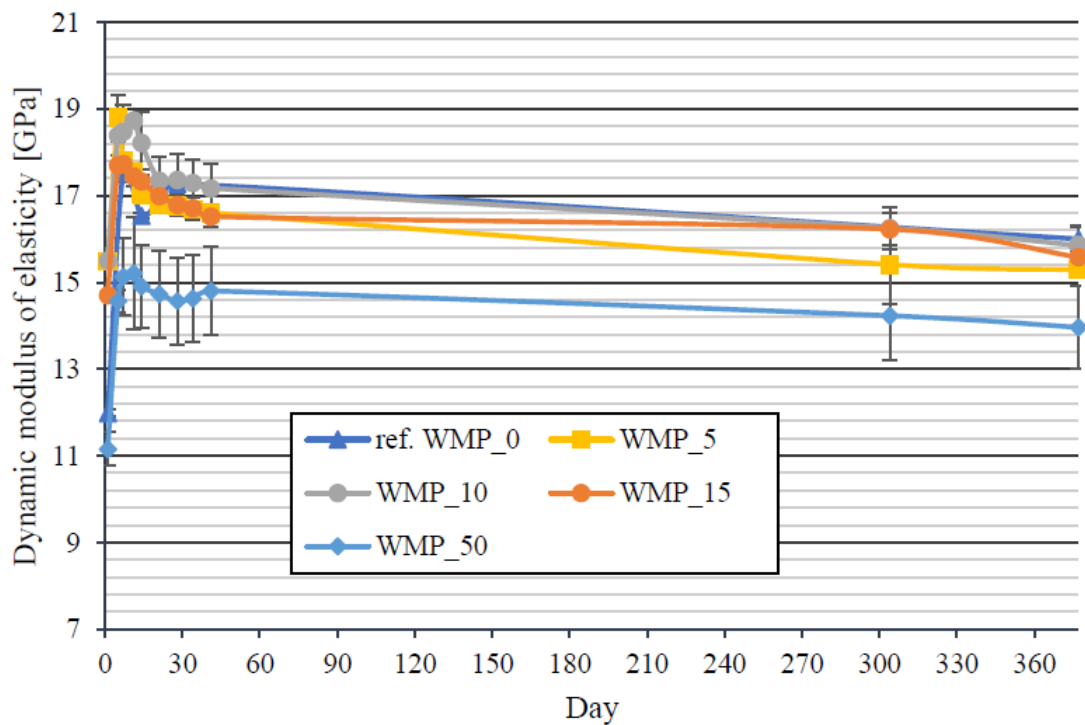

FIGURE 4. Time dependence of dynamic modulus of elasticity (with standard deviation). 
- After the first day, the cement composite rapidly lost the value of modulus, due to loss of weight by gauging water.

- The values of the dynamic modulus of elasticity and the dynamic shear modulus were stabilized between 7 and 377 days. The curves got smaller decline modulus between 7 and 377 days.

\section{ACKNOWLEDGEMENTS}

This outcome was supported by the Czech Technical University in Prague under No. SGS16/201/OHK1/3T/11 and No. SGS17/060/OHK1/1T/11 and by the Ministry of Education, Youth and Sports within National Sustainability Programme I, project No. LO1605.

\section{REFERENCES}

[1] P. Tesárek, K. Šeps, J. Topič, et al. Influence of recycled materials on resulting mechanical properties of cement composites. In Modern Methods of Experimental and Computational Investigations in Area of Construction, vol. 825 of Applied Mechanics and Materials, pp. 53-56. Trans Tech Publications, 2016. DOI:10.4028/www.scientific.net/AMM.825.53

[2] V. Corinaldesi, G. Moriconi. Behaviour of cementitious mortars containing different kinds of recycled aggregate. Construction and Building Materials 23(1):289 - 294, 2009. DOI:10.1016/j.conbuildmat.2007.12.006

[3] J. Topič, Z. Prošek, J. Hrůza. Mechanical properties of the cement paste with fine ground recycled concrete depending on the microstructure. In Modern Methods of Experimental and Computational Investigations in Area of Construction II, vol. 1144 of Advanced Materials Research, pp. 22-27. Trans Tech Publications, 2017. DOI:10.4028/www.scientific.net/AMR.1144.22

[4] Z. Prošek, A. Osvald, J. Topič, et al. Influence of recycled concrete composition on its elastic stiffness. In Key Engineering Materials, vol. 677, pp. 288-291. Trans Tech Publ, 2016.

[5] M. El-Gammal, M. Ibrahim, E. Badr, et al. Health risk assessment of marble dust at marble workshops. Nature and Science 9(11):144-154, 2011.

[6] K. K. Alzboon, K. N. Mahasneh. Effect of using stone cutting waste on the compression strength and slump characteristics of concrete. International Journal of Environmental Science and Engineering 1(4):167-172, 2009 .

[7] L. Lopes, R. Martins. Marbles from portugal. Naturstein, online publication, naturalstone-online com 2012.
[8] S. Shahidan, I. Isham, N. Jamaluddin. A review on waste minimization by adopting in self compacting concrete. In MATEC Web of Conferences, vol. 47. EDP Sciences, 2016.

[9] Z. Prošek, J. Trejbal, J. Topič, et al. Utilization of the waste from the marble industry for application in transport infrastructure: mechanical properties of cement pastes. In IOP Conference Series: Materials Science and Engineering, vol. 236, p. 012092. IOP Publishing, 2017.

[10] A. A. Aliabdo, A. E. M. A. Elmoaty, E. M. Auda. Re-use of waste marble dust in the production of cement and concrete. Construction and building materials 50:28-41, 2014.

[11] A. Ergün. Effects of the usage of diatomite and waste marble powder as partial replacement of cement on the mechanical properties of concrete. Construction and Building Materials 25(2):806-812, 2011.

[12] B. Demirel. The effect of the using waste marble dust as fine sand on the mechanical properties of the concrete. International journal of physical sciences 5(9):1372-1380, 2010.

[13] G. Menéndez, V. Bonavetti, E. Irassar. Strength development of ternary blended cement with limestone filler and blast-furnace slag. Cement and Concrete Composites 25(1):61-67, 2003.

[14] K. Šeps, J. Topič, Z. Prošek. The effect of micronized waste marble powder as partial replacement for cement on resulting mechanical properties of cement pastes. In Modern Methods of Experimental and Computational Investigations in Area of Construction II, vol. 1144 of Advanced Materials Research, pp. 54-58. Trans Tech Publications, 2017. DOI:10.4028/www.scientific.net/AMR.1144.54

[15] Z. Prošek, L. Hlubocký. Mechanical properties of cement composite with material based on waste marble powder and crushed limestone. In Modern Methods of Experimental and Computational Investigations in Area of Construction II, vol. 1144 of Advanced Materials Research, pp. 9-13. Trans Tech Publications, 2017. DOI:10.4028/www.scientific.net/AMR.1144.9

[16] J. Topič, Z. Prošek, K. Indrová, et al. Effect of PVA modification on properties of cement composites. Acta Polytechnica 55(1):64-75, 2015.

[17] Z. Prošek, K. Šeps, J. Topič. The effect of micronized waste marble powder as partial replacement for cement on resulting mechanical properties of cement pastes. In Advanced Materials Research, vol. 1144, pp. 54-58. Trans Tech Publ, 2017. 